\title{
Persistent Mullerian duct Syndrome in a Brazilian miniature schnauzer dog
}

\author{
DENISE M. NOGUEIRA ${ }^{1}$, JORGE L.A. ARMADA ${ }^{1}$, DIEGO M. PENEDO ${ }^{2}$, \\ VANIA G.S. TANNOUZ ${ }^{3}$ and VICKI N. MEYERS-WALLEN ${ }^{4}$ \\ ${ }^{1}$ Departamento de Genética, Instituto de Ciências Biológicas e da Saúde, Universidade Federal \\ Rural do Rio de Janeiro/UFRRJ, BR 465, Km 7, 23897-000 Seropédica, RJ, Brazil \\ ${ }^{2}$ Programa de Pós-Graduação em Biologia Animal, Instituto de Ciências Biológicas e da Saúde, Universidade \\ Federal Rural do Rio de Janeiro/UFRRJ, BR 465, Km 7, 23897-000 Seropédica, RJ, Brazil \\ ${ }^{3}$ Rua Professor Valadares, 171, Grajaú, 20561-020 Rio de Janeiro, RJ, Brazil \\ ${ }^{4}$ James A. Baker Institute for Animal Health, College of Veterinary Medicine, Cornell University, Ithaca, NY 14853, USA \\ Manuscript received on July 23, 2018; accepted for publication on November 9, 2018
}

\begin{abstract}
How to cite: NOGUEIRA DM, ARMADA JLA, PENEDO DM, TANNOUZ VGS AND MEYERS-WALLEN VN. 2019. Persistent Mullerian duct Syndrome in a Brazilian miniature schnauzer dog. An Acad Bras Cienc 91: e20180752. DOI 10.1590/0001-3765201920180752.
\end{abstract}

\begin{abstract}
Here we describe an eight-year-old miniature schnauzer (MS) dog from Brazil with Persistent Mullerian Duct Syndrome (PMDS) and the single base pair substitution in AMHR2 exon 3, first detected in this breed in the USA. This finding is evidence of mutation dissemination to South America. In PMDS, a type of XY Disorder of Sex Development (DSD), dogs with a male karyotype and external phenotype also have a uterus, oviducts, and a cranial vagina internally. Approximately half of PMDS MS are unilaterally or bilaterally cryptorchid and many develop pyometra and/or Sertoli cell tumor. Bilateral Sertoli cell testicular tumors were present in this case, and the dog died a few days after surgical castration and hysterectomy. Although the karyotype was compatible with male chromosomal sex, a Robertsonian translocation was also identified, which may be an incidental finding. This report emphasizes the importance of cytogenetic and molecular genetic analyses, along with clinical examination, to identify chromosomal or genetic variations associated with canine PMDS. These are helpful tools to obtain early diagnosis in the MS, which is important to improve health outcomes for affected dogs and to reduce the prevalence of PMDS and cryptorchidism in this breed by avoiding the mating of carriers.
\end{abstract}

Key words: 78,XY Disorders of Sex Development, AMHR2 exon 3 mutation, canine, PMDS.

\section{INTRODUCTION}

The nomenclature 'disorders of sex development' (DSDs) was proposed to replace the term intersex for humans (Hughes et al. 2006) and dogs (Meyers-Wallen et al. 1989) exhibiting atypical chromosomal, gonadal, or anatomical sex

Correspondence to: Denise Monnerat Nogueira

E-mail: denisemn@ufrrj.br

ORCid: https://orcid.org/0000-0002-7028-0031 development (Hughes 2008). Categories included are chromosomal DSD, XY DSD, and XX DSD (Pasterski and Hughes 2010). In human XY DSD, the main clinical findings are often gonadal anomaly and ambiguous genitalia in a chromosomally male $(46, X Y)$ individual. Diagnostic testing often includes hormone assays, pelvic ultrasonography and molecular analysis for genetic mutations (Ono and Harley 2013). 
Due to molecular advances, gene mutations responsible for canine DSD are being identified. For example, Persistent Mullerian Duct syndrome (PMDS), a type of XY DSD, is prevalent in the miniature schnauzer breed (Smit et al. 2018), but has also been identified in a basset-hound and in a mixed-breed dog (Nickel et al. 1992, Kuiper et al. 2004) as well as in humans (Ren et al. 2017), cattle (Jost 1965), goats (Haibel and Rojko 1990) and cats (Schulman and Levine 1989).

Human PMDS is caused by mutations in Anti Mullerian hormone gene $(A M H)$, also known as Mullerian inhibiting substance (MIS), or its Type II receptor gene (AMHR2, MISRII). Several AMH mutations have been identified in affected humans. A 27 bp deletion in $A M H R 2$ exon 10 accounts for $25 \%$ of PMDS cases with known receptor defects (Imbeaud et al. 1996). A single base pair substitution in AMHR2 exon 3 is less common in PMDS humans (Imbeaud et al. 1996), but is the only canine mutation reported in PMDS dogs (Wu et al. 2009, Smit et al. 2018). The mutation site was first described and have been indicated as c. 241C $>$ T (Wu et al. 2009, Smit et al. 2018) but seven additional amino acids has been identified for the canine $A M H R 2$ protein (NCBI Reference Sequence XP_543632.4) changing this position to c. $262 \mathrm{C}>\mathrm{T}$. This start site was predicted by automated computational analysis from a genomic sequence using the Gnomon gene prediction method (https:// www.ncbi.nlm.nih.gov/protein/545545308/).

The mutation produces a stop codon (Imbeaud et al. 1996) that truncates the AMHR2 peptide during translation, eliminating downstream domains required for receptor function. It was first described in the USA in the miniature schnauzer, where PMDS is inherited as an autosomal recessive trait (Wu et al. 2009). The mutant allele frequency of 0.16 and a carrier genotypic frequency of 0.27 was found in a miniature schnauzer cohort of 216 individuals (including a positive control) from Minnesota, USA (Smit et al. 2018). PMDS in this breed has been reported in several countries (Brown et al. 1976, Marshall et al. 1982, Volino et al. 2003, Matsuu et al. 2009, Vegter et al. 2010, Breshears and Peters 2011, Paz et al. 2017), suggesting the mutation is likely present worldwide (MeyersWallen 2012). A molecular diagnostic test is available (Pujar and Meyers-Wallen 2009).

PMDS dogs reported to date are described as 78 , XY males with normal male external genitalia, except that only $50 \%$ have bilaterally descended testes, and the remainder are either unilaterally or bilaterally cryptorchid (Meyers-Wallen et al. 1989). Those with bilateral cryptorchidism are sterile, but those with unilateral cryptorchidism or descended testes are fertile (Wu et al. 2009). Affected dogs have bilateral oviducts and epididymis adjacent to the testes, vas deferens, a uterus and cervix, and the cranial portion of the vagina (Meyers-Wallen et al. 1989). PMDS dogs are often presented for examination due to cryptorchidism, but may also present with pyometra and/or Sertoli cell tumor (Marshall et al. 1982, Wu et al. 2009, Paz et al. 2017).

The objectives of this report were to identify a PMDS-associated mutation in a miniature schnauzer from Brazil, and to alert clinicians that early diagnosis is crucial to improve health outcomes for affected dogs and reduce PMDS and cryptorchidism in the breed.

\section{MATERIALS AND METHODS}

An eight-year-old miniature schnauzer with male phenotype was presented for examination due to hematuria and polyuria suggestive of urinary infection. During examination by transabdominal ultrasound, a tubular structure, cranial to the prostate and dorsal to the urinary bladder, was identified as a uterus and cranial vagina. Nodular structures were identified in both scrotal testes. With the owner's permission, a blood sample was collected for genetic analysis. The internal genitalia and testes 
were surgically removed. The presence of a uterus and bilateral oviducts, and absence of ovaries was confirmed by gross appearance. Bilateral sertolioma was confirmed by histopathology. The dog died a few days after surgery from unknown causes. The karyotype was analyzed from whole blood culture (Moorhead et al. 1960). Genomic DNA extracted from blood was assayed by PCR using canine specific primers for the Y-linked $S R Y$ gene (Meyers-Wallen et al. 1995), which initiates testis development in mammals. To screen for the canine PMDS mutation we used PCR primers to amplify a portion of AMHR2 exon 3, generating a $\sim 330$ bp product, and a control reaction, assayed in parallel, amplified $A M H R 2$ exon 10, generating a $\sim 437$ bp product (Wu et al. 2009). PCR products were submitted for bidirectional sequencing using Applied Biosystems BigDye V1.1 chemistry (Wu et al. 2009).

\section{RESULTS AND DISCUSSION}

Analysis of metaphase chromosome spreads revealed a $77, \mathrm{XY}, \mathrm{t}(1 ;$ ?) karyotype (Figure 1). Although this result is compatible with male chromosomal sex, the submetacentric chromosome in pair 1, representing a Robertsonian translocation, is an unexpected finding. All reported PMDS dogs analyzed have had a normal male karyotype $(78, X Y)$, where all autosomes are acrocentric. Conventional chromosome staining did not allow precise identification of the translocated chromosome, but its size is comparable to dog chromosome pair 27. While the translocation may be unrelated to PMDS, we note that fertility is reduced to one third in bovine Robertsonian translocation cases (Gustavsson 1979). The affected miniature schnauzer was $S R Y$ positive (Figure 1), as reported for other cases of PMDS. By sequencing the PCR products, the $A M H R 2$ mutation, c. $262 \mathrm{C}>\mathrm{T}$, was identified in exon 3 (Figure 2). No abnormalities were detected in exon 10 .

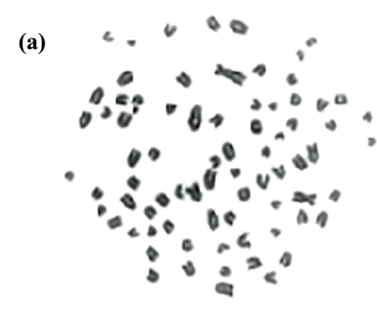

(b)

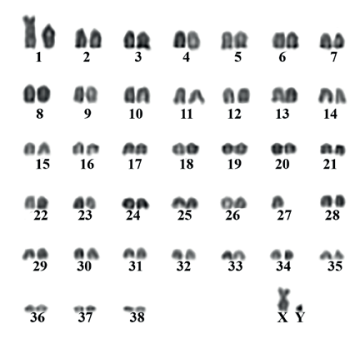

Figure 1 - a Unbanded karyotype of the miniature schnauzer dog with Persistent Mullerian duct Syndrome, showing a Robertsonian translocation $2 \mathrm{n}=77, \mathrm{XY}, \mathrm{t}(1 ;$;). The translocated chromosome is comparable in size to chromosome pair 27. b Canine SRY PCR product ( $104 \mathrm{bp})$ amplified from DNA templates from the PMDS dog and canine controls. $\mathrm{L}-1 \mathrm{~kb}$ ladder, $\mathrm{M}$ - normal male, F - normal female, Sch - case with PMDS and $\mathrm{N}$ - negative (water) control.

This is the first identification of this mutation in a PMDS miniature schnauzer in South America. These results emphasize the importance of cytogenetic and molecular genetic analyses, along with clinical examination, to identify chromosomal and/or genetic variations associated with canine PMDS. This report also illustrates the importance of genetic analysis for early diagnosis. This can reduce morbidity by treating dogs that are healthy surgical candidates avoiding the development of pyometra or Sertoli cell tumors. Early diagnosis and castration can prevent PMDS males from siring carrier or affected pups.

Persistent Mullerian Duct syndrome in the miniature schnauzer has been detected in Europe, Asia, North America and South America. The presence of this disease across the world suggests that it may be appropriate for male miniature schnauzers to be tested for this $A M H R 2$ mutation, whether they present with apparently normal 
1ATGCTGCTTGCCTCCTCCAGCAUGAUGCUGGGGACUCUGGGCCUUUGGGUACUACUUCCC60 61ACAGCUGUGCAAGCACCCCCAAGCAGGCGGACCUGUGUGUUCUUUGAGGCCCCUGGAGUA120 121CGGGGAAGCACAAAGACACUGGGGAAGCUGCUAGAUGCAGGACCAGGGCCCCCCAGGGUU180 181AUCCGCUGCCUCUACAGCCGCUGCUGUUUUGGGAUCUGGAACCUGACCCAAGACCAGGCA240 241CAGGUGGAGAUGCAAGGAUGCTGAGACAGUGAUGAGCCAGACUGUGAGUCCCCCCACUGU 300 301GACCUGAGCCCCCGAGCCCACCCCAGCCCCGGGUCCACUCUCUUCACCUGCUCCUGUGGC360 361ACUGACUUCUGCAAUGCCAAUUACAGCCAU.........

Figure 2 - Nucleotide sequence of the AMHR2 exon 3 product ( $\sim 330 \mathrm{bp})$ amplified by PCR from genomic DNA of the miniature schnauzer from Brazil affected with Persistent Mullerian duct syndrome. The substitution is located at c.262C $>\mathrm{T}$ shown in bold. The authors note that an additional start site has been identified for the canine AMHR2 protein that contains seven additional amino acids (https://www.ncbi.nlm.nih.gov/protein/545545308/).

external genitalia or are cryptorchid, and whether they are breeding stock or pets. PMDS is inherited as an autosomal recessive trait expressed in males, but females can be fertile homozygous or heterozygous carriers (Wu et al. 2009, Smit et al. 2018). Considering the frequency of 0.27 of carrier genotype found for a cohort of this breed in USA, it may be advisable to also test female miniature schnauzers prior to breeding, to avoid matings of carriers. Finally, for any dog testing positive for the AMHR2 mutation, the rest of the pedigree should be screened. This strategy can reduce the frequency of PMDS and cryptorchidism in this breed.

\section{ACKNOWLEDGMENTS}

We thank the attending veterinarian, Dr. Mauricio Portes, for providing the sample for analysis and Dr. Matthew Breen for cytogenetic analysis regarding the translocated chromosome and for his comments, which improved the manuscript.

\section{AUTHOR CONTRIBUTIONS}

DM Nogueira performed the DNA extraction and PCR amplification, analyzed the data and wrote the article, JLA Armada performed the cytogenetic analysis and collaborated in writing the article, DM Penedo collaborated in the cytogenetic analysis, VGS Tannouz performed the ultrasonographic analysis, VN Meyers-Wallen performed the DNA sequencing, identified the mutation and contributed to the writing and review of the article.

\section{REFERENCES}

BRESHEARS MA AND PETERS JL. 2011. Diagnostic Exercise: Ambiguous Genitalia in a Fertile, Unilaterally Cryptorchid Male Miniature Schnauzer Dog. Vet Pathol 48: $1038-1040$

BROWN TT, BUREK JD AND MCENTEE K. 1976. Male pseudohermaphroditism, cryptorchidism and Sertoli cell neoplasia in three Miniature Schnauzers. J Am Vet Med Assoc 169: 821-825.

GUSTAVSSON I. 1979. Distribution and effects of the $1 / 29$ Robertsonian translocation in cattle. J Dairy Sci 62: 825835.

HAIBEL GK AND ROJKO JL. 1990. Persistent müllerian duct syndrome in a goat. Vet Pathol 27: 135-137.

HUGHES IA. 2008. Disorders of sex development: a new definition and classification. Best Pract Res $\mathrm{Cl}$ End 22: 119-134.

HUGHES IA, HOUK C, AHMED SF AND LEE PA. 2006. Consensus statement on management of intersex disorders. Arch Dis Child 91: 554-563.

IMBEAUD S, BELVILLE C, MESSIKA-ZEITOUN L, REY R, DI CLEMENTE N, JOSSO N AND PICARD JY. 1996. A 27 base-pair deletion of the anti-Müllerian type II receptor gene is the most common cause of the persistent Müllerian duct syndrome. Hum Mol Genet 5: 1269-1277.

JOST A. 1965. Gonadal hormones in the sex differentiation of the mammalian fetus. In: Dchaan RL and Ursprung $\mathrm{H}$ (Eds), Organogenesis. Holt, Rinehart and Winston, New York, p. 621-623.

KUIPER H, WAGNER F, DRÖGEMÜLLER C AND DISTL O. 2004. Persistent Mullerian duct syndrome causing male Pseudohermaphroditism in a mixed-breed dog. Vet Rec 155: 400-401. 
MARSHALL LS, OEHLERT ML, HASKINS ME, SELDEN JR AND PATTERSON DF. 1982. Persistent Müllerian duct syndrome in Miniature Schnauzers. J Am Vet Med Assoc 181: 798-801.

MATSUU A, HASHIZUME T, KANDA T, NAGANO M, SUGIYAMA A, OKAMOTO Y AND HIKASA Y. 2009. A case of persistent müllerian duct syndrome with sertoli cell tumor and hydrometra in a dog. J Vet Med Sci 7: 379-381.

MEYERS-WALLEN VN. 2012. Gonadal and sex differentiation abnormalities of dogs and cats. Sex Dev 6: 46-60.

MEYERS-WALLEN VN, BOWMAN L, ACLAND GM, PALMER VL, SCHLAFER D AND FAJT V. 1995. Srynegative XXSR in the German shorthaired pointer. J Hered 86: 369-374.

MEYERS-WALLEN VN, DONAHOE PK, UENO S, MANGARANO TF AND PATTERSON DF. 1989. Müllerian inhibiting substance is present in testes of dogs with persistent Müllerian duct syndrome. Biol Reprod 41: 881-888.

MOORHEAD PS, NOWELL PC, MELLMAN WJ, BATTIPS DM AND HUNGERFORD DA. 1960. Chromosome preparations of leukocytes cultured from human peripheral blood. Exp Cell Res 20: 613-615.

NICKEL RF, UBBINK G, VAN DER GAAG I AND VAN SLUIJS FJ. 1992. Persistent müllerian duct syndrome in the basset hound. Tijdschr Diergeneeskd 117: 31S.

ONO M AND HARLEY VR. 2013. Disorders of sex development: new genes, new concepts. Nat Rev Endocrinol 9: 79-91.

PASTERSKI V AND HUGHES IA. 2010. Impact of the consensus statement and the new DSD classification system. Best Pract Res Cl End 24: 187-195.
PAZ GM ET AL. 2017. Piometra associada a criptorquidismo em cão pseudo-hermafrodita masculino com síndrome da persistência dos ductos de Müller. Rev Bras Reprod Anim 41: 727-731.

PUJAR S AND MEYERS-WALLEN VN. 2009. A molecular diagnostic test for Persistent Mullerian Duct Syndrome in miniature schnauzer dogs. Sex Dev 3: 326-328.

REN X, WU D AND GONG C. 2017. Persistent Müllerian duct syndrome: A case report and review. Exp Ther Med 14: 5779-5784.

SCHULMAN J AND LEVINE SH. 1989. Pyometra involving uterus masculinus in a cat. J Am Vet Med Assoc 194: 690691.

SMIT MM, EKENSTEDT KJ, MINOR KM, LIM CK, LEEGWATER PAJ AND FURROW E. 2018. Prevalence of the AMHR2 mutation in Miniature Schnauzers and genetic investigation of a Belgian Malinois with persistent Müllerian duct syndrome. Reprod Dom Anim 53: 371-376.

VEGTER AR, KOOISTRA HS, VAN SLUIJS FJ, VAN BRUGGEN LWL, IJZER J, ZIJLSTRA C AND OKKENS AC. 2010. Persistent Mullerian duct syndrome in a Miniature Schnauzer dog with signs of feminization and a Sertoli cell tumour. Reprod Domest Anim 5: 447-452.

VOLINO W, GOLDSCHMIDT B, SOUZA L AND LUZ M. 2003. Síndrome da persistência do ducto de Muller em um cão pseudohermafrodita masculino com piometra. Rev Bras Reprod Anim 27: 586-587.

WU X, WAN S, PUJAR S, HASKINS ME, SCHLAFER DH, LEE MM AND MEYERS-WALLEN VN. 2009. A single base pair mutation encoding a premature stop codon in the MIS type II receptor is responsible for canine persistent Müllerian duct syndrome. J Androl 30: 46-56. 